\title{
PRÁTICAS DE AVALIAÇÃO DE PROFESSORES DE CIÊNCIAS FÍSICO-QUÍMICAS DO ENSINO BÁSICO
}

\author{
Physics and Chemistry Middle School \\ teacher's assessment practices
}

\author{
Marisa Sofia Monteiro Correia ${ }^{1}$ \\ Ana Maria Martins Silva Freire ${ }^{2}$
}

Resumo: Na última década em Portugal, tem-se assistido a uma mudança nos currículos valorizando o desenvolvimento de competências de conhecimento (substantivo, processual e epistemológico), de comunicação, de raciocínio e atitudinais, e, em particular, nas orientações curriculares dirigidas à avaliação. Neste contexto, pretende-se caracterizar as práticas de avaliação de professores de Ciências físico-químicas do Ensino Básico. Este estudo envolve três professores em início de carreira. A recolha de dados consiste na observação naturalista de aulas, entrevistas semiestruturadas e documentos fornecidos pelos participantes. Todos os professores demonstram dificuldades na avaliação das competências atitudinais e processuais. Apenas um dos participantes elabora registos de observação para avaliar estas competências. Os testes constituem o principal instrumento de avaliação nas aulas dos professores participantes, o que é coerente com uma perspectiva de ensino e aprendizagem ainda marcadamente tradicional.

Palavras-chave: Avaliação. Práticas avaliativas. Perspectivas de ensino.

\begin{abstract}
During the last decade in Portugal the curricula had undergone several changes, especially towards assessment. In this new curricula competences development is valued in different domains, such as knowledge (substantive, procedural and epistemological), communication, reasoning and attitudinal. In this context, we seek to characterise teachers' assessment practices. This study involves three beginning teachers of chemistry and physics. Data was collected from semi-structured interviews, observations of lessons and documents supplied by the participants. All of the teachers demonstrate difficulties in assessment of attitudinal and procedural competences. Only one of the participants elaborates observation with registration to assess these competences. The tests constitute the main assessment instrument in the teachers' lessons, what is coherent with a teaching and learning perspective that still remains traditional.
\end{abstract}

Keywords: Assessment. Assessment practices. Teaching perspectives.

\footnotetext{
${ }^{1}$ Licenciatura em Química. Doutoranda em Educação. Docente, Núcleo de Ciências Matemáticas e Naturais, Instituto Politécnico de Santarém, Escola Superior de Educação de Santarém (ESES). Santarém, Portugal. <marisa.correia@ese.ipsantarem.pt>

${ }^{2}$ Licenciatura em Química. Doutora em Educação. Docente, Departamento de Educação, Faculdade de Ciências, Universidade de Lisboa (UL). Lisboa, Portugal.<afreire@fc.ul.pt>

${ }^{1}$ Complexo Andaluz

Apartado 131

2001-902 Santarém - Portugal
} 


\section{Introdução}

Nas últimas décadas, a avaliação tem vindo a assumir em Portugal uma importância crescente. Pode mesmo dizer-se que esta tem vindo a ser apontada, por alguns sectores da sociedade e por responsáveis políticos, como resposta a problemas das mais diversas ordens. Fala-se em avaliar os alunos, os professores, as escolas etc., isto ou aquilo, como se tal resolvesse todas as dificuldades. Esta linha de pensamento parece ter subjacente a ideia de que avaliando é possível identificar a origem dos problemas. Avaliar é importante, mas como meio privilegiado para se compreender melhor a situação de modo a intervir de forma fundamentada. A avaliação não se restringe a uma recolha de informação, mas incluindo-a, pressupõe igualmente uma interpretação desses mesmos dados, uma acção orientada por essa interpretação e, assim, uma produção de valores. Enquanto actividade com múltiplas fases, que se interrelacionam, caracteriza-se por um elevado nível de complexidade.

Nos últimos anos em Portugal, tem-se assistido a uma mudança nos currículos e, em particular, nas orientações curriculares dirigidas à avaliação. Reforça-se o uso sistemático da avaliação diagnóstica e formativa pelos professores (GALVÃO et al., 2006) e considera-se que as práticas de avaliação devem ser capazes de criar oportunidades para aprender e constituir fontes de informação tanto para o professor como para o aluno (PONTE et al., 1997). Abrantes (2001) salienta que a posição expressamente adoptada na Reorganização Curricular do Ensino Básico consiste em entender o currículo e a avaliação como componentes integradas de um mesmo sistema. Esta ideia de que a avaliação deve ser parte integrante do processo de ensino-aprendizagem, com o objectivo de melhorar as aprendizagens, informar o professor e os alunos, das suas dificuldades e das suas aprendizagens é defendida por diversos autores (FERNANDES, 2005; EARL, 2003; VALADARES e GRAÇA, 1998; HADJI, 1994; DE KETELE, 1986). Mas estas novas ideias fazem importantes exigências aos professores, implicando mudanças a nível das suas concepções e das suas práticas (BORKO et al., 1997).

Para mudar a avaliação, segundo Earl (2003), é necessário que o professor compreenda que a avaliação e a aprendizagem estão inter-relacionadas. Esta autora define três abordagens de avaliação: avaliação da aprendizagem, avaliação para a aprendizagem e avaliação como aprendizagem. A avaliação que predomina nas escolas é a avaliação da aprendizagem, em que a ênfase é colocada nos produtos, com um carácter essencialmente sumativo, focada na valorização dos conteúdos e cujo objectivo é certificar as aprendizagens dos alunos no final do ano. $\mathrm{Na}$ avaliação para a aprendizagem valoriza-se a vertente formativa, a diversificação de instrumentos de avaliação e tem como finalidade a orientação e regulação do processo de aprendizagem. Na avaliação como aprendizagem o papel do aluno no processo de ensino e aprendizagem e na avaliação é mais activo e determinante no processo; os professores e os alunos decidem em conjunto quais as aprendizagens que devem ser valorizadas e como estas devem ser organizadas e avaliadas.

Numa altura em que passaram poucos anos da Reorganização Curricular no Ensino Básico, torna-se pertinente analisar as práticas avaliativas de professores de Ciências FísicoQuímicas, cuja formação acompanhou as recentes mudanças curriculares, e a forma como integram a avaliação no processo de ensino-aprendizagem. De modo a clarificar os objectivos do estudo, consideram-se as seguintes questões:

1 Que estratégias e instrumentos de avaliação utilizam os professores nas suas práticas?

Ciência \&̊ Educașão, v. 16, n. 1, p. 1-15, 2010 
2 Como articulam as práticas de ensino e de aprendizagem com as práticas de avaliação nas suas aulas?

\section{Revisão de literatura}

O desenvolvimento de competências e atitudes essenciais para aprender a aprender e para lidar com a mudança, assim como para aprender a colaborar e a participar na melhoria da sociedade, através do exercício de uma cidadania esclarecida e activa, são desafios com que a escola se vê confrontada (ALONSO, 2002). A Reorganização Curricular do Ensino Básico aponta para um ensino mais centrado nos alunos, o que implica uma evolução dos professores na adopção de estratégias diversificadas de ensino que permitam o desenvolvimento de competências essenciais (FREIRE, 2004). As Orientações Curriculares (GALVÃO et al., 2002) pretendem contribuir para a alfabetização científica dos jovens, numa sociedade de informação e conhecimento dominada pela ciência e a tecnologia e para o desenvolvimento de competências em diferentes domínios, tais como: o conhecimento (substantivo, processual e epistemológico), raciocínio, comunicação e atitudes. Diversificar e diferenciar os processos de ensino-aprendizagem é o caminho imprescindível para promover o desenvolvimento de competências, o que requer também diversificar os contextos e formas de avaliação.

A finalidade da educação em ciência é a de providenciar, aos alunos, experiências em que tenham a oportunidade de aplicar conhecimento científico, para conhecerem melhor os problemas e dilemas do mundo que os rodeia, desenvolverem competências de conhecimento processual e estratégias de resolução de problemas que caracterizam o inquérito científico. Esta ideia é defendida nas Orientações Curriculares que, como Freire (2004) destaca, apelam para concepções de ensino e aprendizagem de ciência que valorizem o trabalho laboratorial do tipo investigativo, que favoreçam o envolvimento activo dos alunos na sala de aula, passando de ouvintes passivos a actores, e que promovam a relação entre Ciência, Tecnologia, Sociedade e Ambiente.

Uma mudança na forma de abordar o trabalho laboratorial, em direcção a actividades de natureza investigativa, acompanhada por alterações na ênfase dada aos conteúdos e nos modos de conduzir o ensino, pode contribuir decisivamente para melhorar a educação em ciência na escola básica e secundária e para a melhoria do desempenho científico dos alunos portugueses e do nosso país (MIGUÉNS, 2002). Uma actividade laboratorial de carácter aberto demora tempo a ser realizada, o que a torna incompatível com a sua utilização sistemática ao longo de um ano em que há um programa para se cumprir (HODSON, 1996), mas também é certo que ela é mais adequada para promover a aprendizagem de um maior número de competências.

A educação em ciências passou da ênfase nos conteúdos do currículo para uma ênfase nos processos. Enquanto a primeira se baseia na transmissão de conhecimentos, a segunda no desenvolvimento de competências. Como refere Alves (2004, p. 131), "um currículo por competências assume como uma das premissas pedagógicas a de desenvolver, no educando, a capacidade de resolver problemas". Para proporcionar este tipo de aprendizagem é necessário implementar tarefas autênticas, que integram o currículo com questões do dia-a-dia com que o aluno terá de lidar em sociedade e que envolvem um pensamento mais complexo. Tal situa- 
ção obrigará a uma nova forma de conceber instrumentos de avaliação. Pois, tal como enfatiza Valente (1996, p. 104), "o pior inimigo da educação científica são certas formas de avaliação", pois estas orientam os comportamentos sociais dos pais, dos alunos e, por arrastamento, dos próprios professores, assistindo-se, assim, a uma escola que, por causa do seu sistema de avaliação, invalida e transforma por completo todos os objectivos que para si própria definiu.

A avaliação evidencia dois propósitos, como salienta Freire (2004): ajudar o professor a reflectir sobre sua prática, sobre as estratégias usadas e a sua adequação aos alunos, sobre as aprendizagens por estes realizadas e sua importância para o desenvolvimento pessoal e social; e, também, ajudar os alunos a aprender, acompanhando seu envolvimento nas tarefas, referindo sua progressão nas aprendizagens preconizadas e considerando-os individual e colectivamente. Tal acarreta não só necessariamente novas práticas avaliativas, mas, acima de tudo, o desenvolvimento de outro conceito de avaliação.

Segundo Perrenoud (2002), é preciso que as competências sejam avaliadas, de maneira formativa e certificativa, a fim de que a intenção de as usar seja "credível". De outra forma, nem os pais, nem os alunos, nem os professores investirão nelas. Alonso (2002) destaca que a avaliação só poderá ser considerada formativa, quando os alunos se tornam responsáveis pelo seu processo de aprendizagem/avaliação, quando o desenvolvimento de estratégias cognitivas e metacognitivas integra o próprio processo de aprender e de pensar sobre o que se aprende e como se aprende, e quando a construção de conhecimentos é realizada em contextos significativos que permitem ligar o pensar e o agir. Também Peralta (2002) destaca que avaliar competências implica observar os alunos, directa ou indirectamente, na realização de actividades, tão próximas quanto possível de situações autênticas, usando para tal um conjunto de instrumentos que permitam a recolha de evidências sobre o desenvolvimento das competências do aluno ou sobre a sua demonstração em situação. Não esquecendo, porém, que as formas e os modos de avaliação têm de reflectir as aprendizagens realizadas pelos alunos e os resultados obtidos, mas também o empenhamento posto na sua realização. A avaliação de competências não se faz com testes de papel e lápis. Faz-se, sim, em situações reais que não podem ser estandardizadas.

Para Accongio e Doran (1993), os critérios para construir uma avaliação nas ciências efectiva incluem: autenticidade, ou seja, desenvolver instrumentos mais relacionados com a vida real, servindo, assim, aos propósitos do ensino das ciências; registos de avaliação, que sirvam de indicadores do progresso dos alunos; diagnóstico, conhecimento das necessidades de cada aluno; avaliação formativa, colocar a ênfase na avaliação relacionada com o ensino e a evolução do aluno; pensamento crítico, desenvolver uma avaliação que permita desenvolver o pensamento crítico dos alunos e capacidades de resolução de problemas; valores e atitudes, relacionados com a tomada de decisões em questões científicas; aprender a aprender. Tendo em atenção que os objectivos curriculares incluem o desenvolvimento de competências nos domínios dos conhecimentos, raciocínio, atitudes e comunicação, os professores devem procurar formas diversificadas de recolha de elementos para a avaliação dos alunos, recorrendo, além dos testes escritos, a relatórios e outros trabalhos escritos, ao desempenho oral dos alunos e procurar formas práticas e eficazes de registo desses dados, de forma a viabilizar objectivamente a sua inclusão na avaliação sumativa.

As perspectivas que os professores têm sobre a avaliação são um campo gerador de dificuldades e são as causas das resistências dos professores a mudanças nas suas práticas de 
avaliação (RAPOSO, 2006; ALVES, 2004). Segundo Fernandes (2005), continuam a prevalecer modelos que dão ênfase a um ensino tradicional que pouco mais exige dos alunos do que a reprodução de informação previamente transmitida. Estes modelos de avaliação são pouco integrados no ensino e na aprendizagem, mais orientados para a atribuição de classificações do que para a compreensão das dificuldades dos alunos.

A necessidade de mudar e de melhorar as práticas de avaliação das aprendizagens dos alunos deve-se ao facto de estas, como afirma Fernandes (2005), se encontrarem claramente desfasadas das exigências curriculares e sociais com que os sistemas educativos estão confrontados. A forma como a avaliação se organiza e se desenvolve nas salas de aula, nas escolas ou nos sistemas educativos não é independente das concepções que se sustentam acerca da aprendizagem. Pelo contrário, há quase uma relação de causa-efeito entre o que pensamos, ou o que sabemos, acerca das formas como os alunos aprendem e as formas como avaliamos as suas aprendizagens.

A mudança nas práticas avaliativas passa por uma alteração da forma como os professores percepcionam o ensino, para que este deixe de ser focado na figura do professor e que promova o desenvolvimento de competências por meio de estratégias diversificadas. Pacheco (1995) salienta que não basta mudar a avaliação para mudar o sistema, exige-se uma reflexão conjunta sobre as estratégias de mudança e de inovação. A reforma e a inovação não equivalem a mudanças legislativas e pontuais mas, acima de tudo, a mudanças nas práticas, nos comportamentos e nas mentalidades dos intervenientes.

\section{Metodologia}

Este estudo privilegia uma metodologia qualitativa de natureza descritiva e interpretativa, que, segundo Bogdan e Biklen (1994, p. 70), é a mais adequada quando o objectivo da investigação é o de "[...] melhor compreender o comportamento e experiência humanas". Realizaram-se três estudos de caso com o objectivo de se compreenderem as razões das práticas utilizadas na sala de aula e as concepções manifestadas pelos professores, tendo em consideração o contexto em que se inserem. Seguidamente, descrevem-se os participantes, os processos de recolha de dados e de análise dos dados.

Os participantes possuem licenciatura com estágio integrado. Este corresponde a um ano de prática pedagógica supervisionada por um professor da escola secundária e três professores (educação, física e química) da Faculdade de Ciências (Tabela 1). 
Correia, M. S. M.; Freire, A. M. M. S.

Tabela 1. Caracterização profissional e académica dos participantes.

\begin{tabular}{|c|c|c|c|c|c|c|c|}
\hline Nome & Idade & $\begin{array}{l}\text { Habilitações } \\
\text { académicas }\end{array}$ & $\begin{array}{l}\text { Habilitações } \\
\text { profissionais }\end{array}$ & $\begin{array}{c}\text { Situação } \\
\text { profissional }\end{array}$ & $\begin{array}{c}\text { Anos de } \\
\text { serviço }\end{array}$ & Disciplina/Ano & Cargos \\
\hline A & 28 & $\begin{array}{l}\text { Licenciatura no } \\
\text { Ensino da Física } \\
\text { e da Química }\end{array}$ & $\begin{array}{l}\text { Estágio } \\
\text { integrado }\end{array}$ & Contratado & 3 & $\begin{array}{l}\text { Ciências Físico- } \\
\text { Químicas } \\
\left(7^{\circ}, 8^{\circ} \text { e } 9^{\circ}\right)\end{array}$ & $\begin{array}{l}\text { Director de } \\
\text { turma; } \\
\text { Coordenador de } \\
\text { departamento }\end{array}$ \\
\hline B & 24 & $\begin{array}{l}\text { Licenciatura no } \\
\text { Ensino da Física } \\
\text { e da Química }\end{array}$ & $\begin{array}{l}\text { Estágio } \\
\text { integrado }\end{array}$ & Contratada & 3 & $\begin{array}{l}\text { Ciências Físico- } \\
\text { Químicas } \\
\left(7^{\circ}, 8^{\circ} \text { e } 9^{\circ}\right)\end{array}$ & _ \\
\hline C & 25 & $\begin{array}{l}\text { Licenciatura no } \\
\text { Ensino da Física } \\
\text { e da Química }\end{array}$ & $\begin{array}{l}\text { Estágio } \\
\text { integrado }\end{array}$ & Contratado & 3 & $\begin{array}{l}\text { Ciências Físico- } \\
\text { Químicas }\left(8^{\circ}\right) \\
\text { Físico-Química }\left(11^{\circ}\right)\end{array}$ & Director de turma \\
\hline
\end{tabular}

A recolha de dados realizada recorreu a três técnicas apontadas por diversos autores (YIN, 2003; BOGDAN e BIKLEN, 1994; PATTON, 1990; MERRIAM, 1988), como as mais aconselháveis para os estudos de caso qualitativos: a entrevista, de características semiestruturadas; a observação directa, com pouco cariz de participação; e a análise documental. A utilização destes instrumentos constitui uma forma de obtenção de dados de diferentes tipos, a qual proporciona a possibilidade de cruzamento de informação. A entrevista inicial realizada está estruturada em três grandes blocos - percurso académico e profissional, ensino e aprendizagem, e avaliação.

Pretende-se, com esta primeira entrevista, recolher dados que permitam: (a) obter informação acerca da formação académica e, principalmente, do percurso profissional dos professores; (b) averiguar acerca das práticas avaliativas dos professores; e (c) averiguar acerca da integração da avaliação no processo de ensino-aprendizagem. As questões, apesar de constarem do guião, não obedecem a uma ordem rígida. Estas são exploradas e aprofundadas de acordo com as respostas dos professores, permitindo fazer adaptações no decorrer da entrevista. As entrevistas foram gravadas e transcritas pela investigadora. Estas entrevistas iniciais foram posteriormente complementadas por um conjunto de observações directas dos participantes em contexto de aula, das quais se fez um registo áudio.

A observação das aulas permite colher informações sobre as práticas avaliativas dos professores e a forma como integram a avaliação nas actividades realizadas com os alunos. Solicitou-se, a cada professor, que seleccionasse aulas com características diferentes - expositiva, de resolução de exercícios e de actividade laboratorial - para permitir uma recolha de dados mais diversificada. Depois de concluída a série de observações de aulas, realizou-se outra entrevista síntese das observações efectuadas, que permite completar e aprofundar ideias suscitadas nas entrevistas após a observação das aulas e confrontá-las com as práticas observadas.

Para a triangulação dos dados foram recolhidos documentos oficiais e documentos pessoais de cada um dos três participantes (Tabela 2). 
Práticas de avaliação de professores ...

Tabela 2. Instrumentos de recolha de dados e questões de investigação.

\begin{tabular}{|c|c|c|c|c|}
\hline \multirow[t]{3}{*}{ Questões de investigação } & \multicolumn{4}{|c|}{ Recolha de dados } \\
\hline & \multicolumn{2}{|c|}{ Entrevista } & \multirow[b]{2}{*}{ Observação } & \multirow[b]{2}{*}{ Documentos } \\
\hline & Inicial & $\begin{array}{c}\text { Após } \\
\text { observação }\end{array}$ & & \\
\hline Estratégias / Instrumentos de avaliação & $x$ & $x$ & $x$ & $x$ \\
\hline Articulação entre práticas de ensino e práticas de avaliação & $x$ & $x$ & $x$ & \\
\hline
\end{tabular}

A análise de conteúdo das descrições das observações realizadas nas salas de aula dos três professores constitui um suporte de validação da interpretação das entrevistas. Através da observação consegue-se identificar as estratégias e instrumentos de avaliação que os professores implementam nas suas aulas e a forma como integram a avaliação no processo de ensinoaprendizagem.

Os documentos recolhidos nas escolas permitem informar a interpretação da actuação dos professores nos diferentes contextos. Também os documentos elaborados por cada professor permitem validar a interpretação realizada acerca das práticas avaliativas dos professores e, simultaneamente, constituem elementos clarificadores das práticas. De acordo com as questões de investigação, procedeu-se à análise e descrição de cada uma das categorias: as práticas que desenvolvem; e a forma como integram a avaliação no processo de ensino-aprendizagem (Tabela 3).

Tabela 3. Definição das categorias.

\begin{tabular}{|c|c|c|}
\hline Questões de investigação & Categorias & Definição \\
\hline $\begin{array}{l}\text { Estratégias / Instrumentos de } \\
\text { avaliação }\end{array}$ & $\begin{array}{l}\text { Estratégias de recolha de informação } \\
\text { Instrumentos de avaliação }\end{array}$ & $\begin{array}{l}\text { Questionamento } \\
\text { Observação } \\
\text { Documentos escritos (testes, fichas de } \\
\text { trabalho, trabalhos, trabalhos de casa) } \\
\text { Actividades laboratoriais }\end{array}$ \\
\hline $\begin{array}{l}\text { Articulação entre práticas de } \\
\text { ensino e práticas de avaliação }\end{array}$ & $\begin{array}{l}\text { Integração da avaliação no processo } \\
\text { de ensino e aprendizagem }\end{array}$ & $\begin{array}{l}\text { Processo de registo (escrito ou mental) } \\
\text { Estratégias de ensino coincidentes ou } \\
\text { não com as estratégias de avaliação } \\
\text { Retroacção proporcionada aos alunos }\end{array}$ \\
\hline
\end{tabular}

\section{Resultados}

Os resultados estão organizados de forma a descrever, em primeiro lugar, os casos em função das categorias e, posteriormente, uma análise comparativa entre os três casos, procurando responder às questões que orientaram o presente estudo, e, simultaneamente, 
compreender e explicar o significado dos dados reduzidos. Analisam-se possíveis relações entre a forma como os três professores veem o ensino, a aprendizagem e a avaliação, e a forma como a concretizam na prática, evidenciando o que há de comum e o que há de divergente entre os diversos casos, bem como a identificação de conflitos ou problemáticas que podem sobressair da interpretação dos dados que deram o corpo a este estudo.

As práticas de avaliação devem identificar dificuldades e sugerir formas de ajudar os alunos; devem ter como principais funções a compreensão e o melhoramento da prática educativa; devem enfatizar o controlo e o progresso individuais, identificando os pontos fortes e as necessidades dos alunos e consequente adaptação do ensino, por parte do professor. A retroacção, nas suas mais variadas formas, é um processo indispensável para que a avaliação se integre plenamente no processo do ensino-aprendizagem. Torna-se também pertinente compreender como as perspectivas de ensino dos professores se reflectem nas suas práticas de avaliação. A forma como o professor percepciona o papel do aluno, o papel do professor, as finalidades do ensino e as estratégias de ensino que implementa demonstra a perspectiva de ensino do professor, o que, consequentemente, influencia a avaliação que implementa nas suas aulas.

A observação das aulas dos professores permitiu analisar a articulação entre as práticas de ensino e as práticas de avaliação; os resultados evidenciam que existe maior integração entre as práticas dos professores que têm uma concepção de ensino mais afastada da tradicional. As práticas de avaliação dos professores reflectem as suas concepções de ensino, quer na frequência com que utilizam certas estratégias quer no peso que atribuem aos instrumentos de avaliação para classificar os alunos. Os professores que implementam actividades diversificadas e mais centradas nos alunos afastam-se de uma concepção de ensino mais tradicional, valorizam o desenvolvimento de competências de natureza diversa e assumem-se como facilitadores das aprendizagens dos alunos. Estas práticas de avaliação aproximam-se mais de uma avaliação enfatizada nos novos currículos, onde é encarada como parte integrante do processo de ensino-aprendizagem.

O professor A demonstra poucos constrangimentos na profissão, conferindo particular atenção à relação professor/aluno e preocupando-se com aspectos relacionados com a educação para a cidadania. Assume uma relação despreocupada com o currículo, defendendo que o professor deve ter mais preocupações com a forma como trabalha com os seus alunos do que em leccionar todas as temáticas. Na sua perspectiva, as tarefas devem motivar os alunos para a Física e para a Química e permitir a sua participação activa, ficando reservado para o professor o papel de gestor da aprendizagem.

No discurso do professor A, a avaliação tem uma finalidade que vai além da classificação, é a de orientar e regular o processo de ensino-aprendizagem. Para este professor, a avaliação permite não só avaliar o desempenho dos alunos como o do próprio professor, como, por exemplo: o frequente recurso ao questionamento tem o intuito de "perceber qual a dificuldade e ai dar pistas para pensar em maneiras de superar as dificuldades" (Entrevista após a observação, março de 2006). No entanto, apesar do questionamento e da observação dos alunos constituírem, segundo este professor, as principais estratégias de recolha de informação sobre os seus alunos, verifica-se que praticamente não regista estas informações. Os registos que realiza abrangem apenas as atitudes e são ocasionais, como refere: "Tomo notas mas só dos alunos que se destacam positiva e negativamente. E se há alguma situação em que eu veja que há grandes dificuldades para poder mais tarde trabalhar nelas" (Entrevista após a observação de aula, março de 2006). Daí 
se conclui que a informação recolhida pelos registos é deficiente para a regulação do processo de ensino-aprendizagem.

A observação da sua prática lectiva revela que as estratégias e instrumentos de avaliação parecem estar em consonância com um ensino ainda centrado no professor, mas onde o aluno já assume um papel mais interventivo. Embora o teste seja o instrumento de avaliação com maior peso na classificação dos alunos, aposta em actividades diversificadas que permitem o desenvolvimento de um número maior de competências. Destacam-se as actividades laboratoriais, que são frequentes e essencialmente de carácter investigativo. No que se refere ao feedback aos alunos, verifica-se que informa e orienta os alunos na sua aprendizagem, destacando que "é importante o aluno saber onde tem que melhorar... para onde deve dirigir os seus esforços" (Entrevista, dezembro de 2005).

Este professor considera que a avaliação deve estar integrada no processo de ensinoaprendizagem e que as estratégias de ensino e de avaliação são simultâneas. Contudo, verificase que os seus instrumentos de avaliação não lhe permitem avaliar todas as competências, nomeadamente quando implementa actividades laboratoriais não tem qualquer instrumento que recolha evidências acerca das competências processuais desenvolvidas pelos alunos. Outra das discrepâncias entre as suas práticas de ensino e as suas práticas de avaliação está relacionada com o facto de as atitudes que afirma valorizar apresentarem um peso diminuto nas classificações dos alunos.

A professora $\mathrm{B}$ demonstrou ser uma professora dinâmica que se preocupa em diversificar as estratégias de ensino. Na sua opinião, o professor deve ceder o papel principal aos alunos, mas o que se verifica nas suas práticas é que o ensino é centrado quase sempre no professor. Levanta um pouco "a ponta do véu" quando se refere várias vezes ao "comodismo" do professor, como justificação para a não implementação de certas estratégias que conferem maior autonomia ao aluno, deixando assim para trás outros condicionalismos das práticas citados anteriormente, como as dimensões das turmas e o cumprimento dos conteúdos programáticos.

Promove a utilização da avaliação formativa numa perspectiva reguladora da aprendizagem e, ao longo do processo de avaliação, recolhe informações que lhe permitem a adequação de estratégias em conformidade com as dificuldades detectadas nos alunos, como refere: "Existem certas estratégias que mudei [...], porque verifiquei que não obtive bons resultados. [...] fui fazendo ajustes consoante as dificuldades dos alunos" (Entrevista, dezembro de 2005). Procura desenvolver o maior número de competências possível nos seus alunos, destacando, em especial, as atitudes, e baseia as suas decisões numa observação sistemática. Para esse efeito, afirma: "Utilizo uma folha de registos em que tenho vários parâmetros e coloco lá o desempenho dos alunos com uma escala" (Entrevista, dezembro de 2005).

A análise da prática lectiva, baseada na observação de aulas demonstra que as suas práticas de ensino ainda estão muito centradas no professor, nomeadamente em relação ao peso do teste para efeitos de classificação dos alunos. Contudo, as práticas de ensino desta professora parecem afastar-se de um ensino mais tradicional, recorrendo a estratégias diversificadas, como as actividades laboratoriais, ainda que não sejam muito frequentes e apresentem carácter fechado, mas são sempre realizadas pelos próprios alunos.

A retroacção é outro aspecto que não tem um papel importante nas suas aulas. Segundo a professora B, procura dar informações aos alunos sobre o seu desempenho, como salien- 
ta: "Eu tento dar sempre, quanto mais não seja com aquelas palavras - muito bem, boa resposta?' (Entrevista após observação de aula, junho de 2006); no entanto, revela que esta tarefa nem sempre é fácil, a dimensão da turma é uma forte condicionante, referindo que "com trinta é muito difícil..." (Entrevista após observação de aula, maio de 2006).

Verifica-se uma quase simultaneidade entre práticas de ensino e práticas de avaliação desta professora, no entanto, alguns aspectos falham na integração da avaliação no processo de ensino-aprendizagem. $\mathrm{Na}$ implementação das estratégias de ensino, esta professora exibe um cuidado constante em recolher o máximo de evidências sobre o desempenho dos alunos. Porém, essa informação parece ser mais utilizada em termos de classificação do que com o objectivo de orientar o aluno na aprendizagem.

O professor $\mathrm{C}$ revelou-se seguro nas suas práticas e na tomada de decisões. O cumprimento dos programas é fundamental para si e, por vezes, tem que fazer sacrifícios para que a planificação seja cumprida. Esses sacrifícios são decididos, por vezes, em detrimento do aluno na medida em que não modifica as suas estratégias de ensino consoante as dificuldades dos alunos, e, quando o faz, é por motivos de calendarização, como é evidente no seu discurso quando afirma: "Continuei a aplicar o mesmo tipo de aula [...]. Se mudasse seria muito pouco" (Entrevista, dezembro de 2005). Quando detecta que os alunos apresentam dificuldade na aprendizagem de um determinado conteúdo, limita-se a disponibilizar um pouco mais de tempo de aula, sem contudo alterar as suas estratégias, referindo a esse respeito que

\footnotetext{
"bá alguns alunos um bocadinho mais fracos que às vezes na aula não conseguem talvez, acompanhar-me, mas é uma opção que tem que ser feita e eu faço essa opção sem problemas de consciência, [...] os médio/bons também não podem ser prejudicados relativamente aos outros, enquanto que os outros podem ter apoio extra”. (Entrevista, dezembro de 2005)
}

As práticas de ensino do professor $\mathrm{C}$ distinguem-se das práticas de avaliação, evidenciando uma perspectiva de ensino tradicional. Por vezes, dá alguma retroacção aos alunos, mas essa informação parece servir mais a uma função de classificação do que de regulação das aprendizagens. As práticas avaliativas decorrem em momentos específicos, como os testes que constituem o principal instrumento de avaliação, e, ao longo do processo de ensino-aprendizagem, o professor não recorre a qualquer registo escrito, segundo este, apenas mental, para avaliar o desenvolvimento das atitudes e do conhecimento processual. Demonstra ter dificuldades na avaliação deste tipo de competências quando afirma que "é muito complicado avaliar as competências todas em todos os alunos. Há muitas competências que são complicadas de avaliar" (Entrevista, dezembro de 2005). Deixa ainda transparecer que não tem em consideração estas competências quando atribui classificações aos seus alunos, indo contra os critérios de avaliação da sua escola, ao referir que "esses parâmetros de avaliação supostamente obrigatoriamente utilizados, outras vezes escolhe-se só alguns" (Entrevista, dezembro de 2005).

Para o professor C, o papel do professor, em aula, é explicar os assuntos, procurando que os alunos acompanhem a exposição. Como tal, o papel do aluno é seguir o professor, resolver as actividades propostas e participar colocando questões ou respondendo às solicitações directas ou não. Embora reconheça a necessidade de diversificar as estratégias e os ins- 
trumentos de avaliação, nas práticas o que se verifica é que não valoriza instrumentos que envolvam competências de natureza diversa. A resolução de exercícios, a transmissão expositiva de conhecimentos, as demonstrações experimentais acompanhadas de questões colocadas aos alunos e a correcção de testes e trabalhos de casa constituem, grosso modo, as práticas de ensino mais utilizadas por este professor, que visam quase exclusivamente o desenvolvimento de competências, como o raciocínio e o conhecimento substantivo. Utiliza materiais de ensino pouco diversificados, sobressaindo a utilização do manual escolar, quer como suporte das aulas, quer da preparação das mesmas. A realização de trabalhos laboratoriais é pouco frequente nas suas aulas e resumem-se a meras demonstrações realizadas pelo professor, embora tenha à sua disposição os materiais e equipamentos necessários para a realização destas actividades pelos próprios alunos. Este professor evidencia, desta forma, uma perspectiva de ensino tradicional coerente com as suas práticas avaliativas.

Nos discursos dos professores A e B, a avaliação tem uma finalidade que vai além da classificação, é a de orientar e regular o processo de ensino-aprendizagem. Nas práticas destes dois participantes verifica-se uma maior articulação entre práticas de ensino e práticas de avaliação; o primeiro porque fornece feedback regular e sistemático aos alunos e a segunda porque recorre a registos das observações em todas as aulas para fazer um acompanhamento sistemático das aprendizagens e dificuldades dos alunos.

É interessante assinalar que, nas aulas dos professores A e B, desenvolvia-se um ambiente em que os alunos participavam mais activamente na aprendizagem, parecia que os professores tinham mais facilidade em valorizar e em utilizar outras estratégias, técnicas e instrumentos para além dos testes, destacando-se a aposta em actividades laboratoriais. No entanto, no caso do professor B, estas actividades são muito frequentes nas suas aulas e apresentam um carácter investigativo, ao contrário da professora $\mathrm{A}$, apesar de esta professora ter melhores condições e materiais para a realização deste tipo de actividades. Esta professora não implementa com tanta frequência actividades laboratoriais, mas realiza um registo de observações sistemático que envolve todas as competências desenvolvidas pelos alunos. No que diz respeito ao modo como os professores deste estudo entendem o papel do professor e do aluno, existem diferenças mais acentuadas, quando se comparam estes dois casos com o do professor $\mathrm{C}$, que praticamente só implementa estratégias visando a aquisição de conhecimento substantivo, onde o papel do aluno é o de um mero receptáculo de informação.

De um modo geral, nas práticas de todos os participantes deste estudo, verifica-se que a atribuição de classificações está sobretudo dependente dos resultados dos testes, denunciando uma ênfase no desenvolvimento do conhecimento substantivo e do raciocínio em detrimento das atitudes e do conhecimento processual, o que é coerente com uma perspectiva de ensino e aprendizagem ainda, marcadamente, tradicional. Os professores revelam ter várias dificuldades na integração da informação que têm disponível, que é de natureza diversificada. Muito provavelmente porque não lhes é igualmente fácil estabelecer critérios que os ajudem a fazer corresponder as aprendizagens dos alunos a um dado valor de uma dada escala. Todos os participantes no estudo demonstram dificuldades na avaliação das competências atitudinais e processuais, sendo que apenas a professora B procede ao registo de observações, os outros professores argumentam dispor de pouco tempo para a utilização de registos escritos, assim, não é clara a forma como avaliam estas competências. A retroacção aos alunos ao longo do processo de ensino-aprendizagem é pouco frequente, à excepção do caso do professor A. 
Salienta-se ainda o facto de nenhum dos participantes se referir à avaliação da competência de comunicação, o que sugere um afastamento das competências preconizadas nas orientações curriculares.

\section{Conclusão e discussão}

Apesar das propostas avaliativas inovadoras, integradas nos documentos da Reorganização Curricular do Ensino Básico, o que as práticas de avaliação dos participantes, na sua globalidade, demonstram é o peso desmesurado do teste sumativo na avaliação dos alunos, e que os instrumentos ditos de avaliação formativa - listas de verificação, escalas de verificação, grelhas de observação, registos de incidentes críticos - são muito pouco utilizados pelos professores e, desta forma, não será possível avaliar o percurso seguido pelo aluno (TAMIR, 1990). Parece sentir-se, por parte dos participantes, ainda a necessidade de medir os conhecimentos e comportamentos observáveis, através de instrumentos em que acreditam, que se lhes apresentam como rigorosos e fiáveis, os testes escritos. Contudo, verifica-se que dois dos participantes, Leonor e Francisco, se aproximam de uma concepção de avaliação para a aprendizagem (EARL, 2003) em que há maior integração da avaliação no processo de ensinoaprendizagem, num caso devido ao registo sistemático das aprendizagens dos alunos e, no outro caso, prende-se com a informação constante aos alunos acerca da sua evolução. As práticas de avaliação de Pedro deixam claro uma concepção de avaliação da aprendizagem (EARL, 2003), em que avaliação surge em momentos específicos, essencialmente nos testes, desfasada do processo de ensino-aprendizagem.

As práticas avaliativas parecem caracterizar-se por estratégias visando os conhecimentos adquiridos, esquecendo-se os processos mais complexos de pensamento e os aspectos mais ligados aos interesses, atitudes e valores. As práticas dos participantes revelam-se demasiado centradas no ensino de factos, pouco apelativas ao desenvolvimento de capacidades práticas, da curiosidade, espírito crítico e criatividade nos alunos. Estas práticas contrariam a ideia de um ensino direccionado para o desenvolvimento de competências de natureza diversa em que avaliar, como salientam Peralta (2002) e Alves (2004), implica observar os alunos, na realização de actividades, tão próximas quanto possível de situações autênticas, usando para tal um conjunto de instrumentos que permitam a recolha de evidências sobre o desenvolvimento das competências do aluno. A avaliação tem que acompanhar o desenvolvimento, nos alunos, de competências tão importantes como as demais e que são remetidas, como se constatou neste estudo, para um segundo plano, como: o conhecimento processual, a comunicação e as atitudes.

$\mathrm{O}$ facto do trabalho laboratorial não ser muito implementado pelos professores e o recurso a demonstrações, como se verificou no âmbito do estudo nalguns participantes, poderá significar que as competências processuais não são muito valorizadas. Neste sentido, constatou-se, ainda, que os professores com melhores condições nas suas escolas são os que recorrem menos ao trabalho laboratorial, o que vai de encontro ao que defendem alguns autores (HOFSTEIN e LUNETTA, 1982) de que a existência de equipamento e material não garante o desenvolvimento conceptual. Apenas um dos participantes implementa actividades labora-

toriais de cariz investigativo, o que evidencia ainda dificuldade por parte dos professores em 
conferir maior autonomia aos alunos e compreender a importância de competências como as atitudes e a comunicação. À semelhança de resultados de outros estudos (SANTOS, 1999; ALMEIDA, 1995; RUIVO, 1994), este estudo revela uma relação entre concepções e práticas em sala de aula relacionadas com a realização de trabalho laboratorial, na medida em que os participantes que promovem actividades laboratoriais cuja concepção, realização e exploração estão centradas no professor evidenciam uma perspectiva tradicional do ensino das ciências.

Embora os discursos dos professores participantes demonstrem estar concordantes com o das Orientações Curriculares para o Ensino Básico, no sentido do desenvolvimento de competências, verifica-se que as suas práticas de ensino são ainda centradas no professor, em que os alunos não têm ainda um papel interventivo durante o processo, para, desta forma, regularem a sua própria aprendizagem. Esta dificuldade em realizar na prática aquilo em que dizem acreditar, poderá indicar que outros factores de ordem externa condicionam as práticas, como: as características dos alunos, as dimensões das turmas, as condições materiais da escola. Perrenoud (1999) refere que a avaliação formativa e a pedagogia diferenciada chocam-se com obstáculos materiais e institucionais numerosos: o efeito das turmas, a sobrecarga dos programas e a concepção dos meios de ensino e das didácticas, que quase não privilegiam a diferenciação. O horário escolar, a ordenação dos espaços são restrições dissuasivas para quem não sente, visceralmente, a paixão pela igualdade. Tillema (2000) também salienta que as condições da prática podem facilitar ou inibir a mudança no professor, especialmente no período complexo e desafiante dos primeiros anos de serviço.

Prevalece nestes professores a ideia de que as actividades de avaliação retiram tempo das actividades de ensino. Esta ideia poderá ser combatida quando os professores se aperceberem que podem usar as estratégias de avaliação e de ensino para os mesmos objectivos (BORKO

et al., 1997). É imprescindível que as concepções dos professores evoluam no sentido de se afastarem de uma perspectiva de ensino tradicional, para que ocorra, de facto, uma mudança real nas suas práticas de ensino.

\section{Referências}

ABRANTES, P. Reorganização curricular do ensino básico: princípios, medidas e implicações. Lisboa: Ministério da Educação, 2001.

ACCONGIO, J.; DORAN, R. Classroom assessment: key to reform in secondary science education. Columbus: ERIC/CSMEE, 1993.

ALMEIDA, A. Trabalho experimental na educação em ciência: Epistemologia, representações e práticas dos professores. 1995. 259f. Dissertação (Mestrado em Educação) - Faculdade de Ciências e Tecnologia, Universidade Nova de Lisboa, Lisboa, 1995.

ALONSO, L. Integração currículo-avaliação. Que significados? Que constrangimentos? Que implicações? In: ABRANTES, P.; ARAÚJO, F. (Orgs.). Avaliação das aprendizagens: das concepções às práticas. Lisboa: Ministério da Educação, 2002. p. 17-23. 
Correia, M. S. M.; Freire, A. M. M. S.

ALVES, M. Currículo e avaliação: uma perspectiva integrada. Porto: Porto Editora, 2004.

BOGDAN, R.; BIKLEN, S. Investigação qualitativa em educação: uma introdução à teoria e aos métodos. Porto: Porto Editora, 1994.

BORKO, H. et al. Teachers' developing ideas and practices about mathematics performance assessment: Sucesses, stumbling blocks, and implications for professional development. Teaching and Teacher Education, Amsterdam, v. 13, n. 3, p. 259-278, 1997.

DE KETELE, J. A propósito das noções de avaliação formativa, de avaliação sumativa, de individualização e de diferenciação. In: ALLAL, L.; CARDINET, J.; PERRENOUD, P. (Orgs.). A avaliação formativa num ensino diferenciado. Coimbra: Livraria Almedina, 1986. p. 211-218.

EARL, L. M. Assessment as learning: using classroom assessment to maximize student learning. California: Corwin Press, 2003.

FERNANDES, D. Avaliação das aprendizagens: desafios às teorias, práticas e políticas. Lisboa: Texto Editores, 2005.

FREIRE, A. M. Mudança de concepções de ensino dos professores num processo de reforma curricular/change teachers' teaching conceptions in a process of curricular reform. In: MINISTÉRIO DA EDUCAÇÃO (Org.). Flexibilidade curricular, cidadania e comunicação/Flexibility in curriculum, citzenship and communication. Lisboa: Ministério da Educação, 2004. p. 265-280.

GALVÃO, C. et al. Avaliação das competências em ciências: sugestões para professores do Ensino Básico e Secundário (Prática e Teoria). Porto: Edições ASA, 2006.

- Ciências físicas e naturais: orientações curriculares para o $3^{\circ}$ ciclo do ensino básico. Lisboa: Ministério da Educação, 2002.

HADJI, C. A avaliação, regras do jogo: das intenções aos instrumentos. Porto: Porto Editora, 1994.

HODSON, D. Practical work in school science: exploring some directions for change.

International Journal of Science Education, London, v. 18, n. 7, p. 755-760, 1996.

HOFSTEIN, A.; LUNETTA, V. The role of the laboratory: neglected aspects of research. Review of Educational Research, Washington, v. 52, n. 2, p. 201-217, 1982.

MERRIAM, S. B. Case study research in education: a qualitative approach. San Francisco: Jossey Bass, 1988.

MIGUÉNS, M. O trabalho prático e a "reinvenção" de escola. In: COELHO, A. C. et al. (Orgs.). Educação em ciência: VII Encontro Nacional. Faro: Escola Superior de Educação - Universidade do Algarve, 2002. p. 28-43.

PACHECO, J. A. A avaliação dos alunos na perspectiva da reforma. Porto: Porto Editora, 1995. 
Práticas de avaliação de professores ...

PATTON, M. Q. Qualitative evaluation methods. Newbury Park: Sage Publications, 1990.

PERALTA, H. Como avaliar competências? In: ABRANTES, P.; ARAÚJO, F. (Orgs.). Avaliação das aprendizagens: das concepções às práticas. Lisboa: Ministério da Educação, 2002. p. 55-64.

PERRENOUD, P. A escola e a aprendizagem da democracia. Porto: Edições ASA, 2002.

Avaliação: da excelência à regulação das aprendizagens - entre duas lógicas. Porto Alegre: Artmed, 1999.

PONTE, J. P. et al. Didáctica da matemática: ensino secundário. Lisboa: Ministério da Educação, 1997.

RAPOSO, P. Concepções sobre avaliação das aprendizagens: um estudo com professores de Física e Química. 2006. 194f. Dissertação (Mestrado em Educação) Faculdade de Ciências, Universidade de Lisboa, Lisboa, 2006.

RUIVO, M. Representações dos professores acerca do trabalho prático em geologia na disciplina de ciências naturais do $7^{\circ}$ ano de escolaridade. 1994. 225f. Dissertação (Mestrado em Educação) - Instituto de Estudos da Criança, Universidade do Minho, Lisboa, 1994.

SANTOS, A. Trabalho experimental em educação em ciências: concepções e práticas dos professores. 1999. 242f. Dissertação (Mestrado em Educação) - Instituto de Estudos da Criança, Universidade do Minho, Lisboa, 1999.

TAMIR, P. Evaluation of student laboratory work and its role in developing policy. In: HEGGARTY-HAZEL, E. (Org.). The student laboratory and the science curriculum. Londres: Routledge, 1990. p. 242-266.

TILLEMA, H. Belief change towards self-directed learning in student teachers: immersion in practice or reflection on action. Teaching and Teacher Education, Amsterdam, v. 16, n. 5/6, p. 575-591, 2000.

VALADARES, J.; GRAÇA, M. Avaliando para melhorar a aprendizagem. Lisboa: Plátano Editora, 1998.

VALENTE, M. O ensino das ciências em Portugal. Revista de Educação, Lisboa, v. 6, n. 1, p. 103-104, 1996.

YIN, R. Case study research: design and methods. Thousand Oaks: Sage Publications, 2003.

Artigo recebido em fevereiro de 2010 e aceito em março de 2010. 